\title{
STUDY ON THE MANAGEMENT OF NEW GENERATION EMPLOYEE SEPARATION IN STATE-OWNED COMMERCIAL BANKS: TAKE X BANK AS AN EXAMPLE
}

\author{
Huangrongshang Chen
}

Rangsit University, Bangkok, Thailand

After China's financial industry having entered into rapid development with China's accession to the WTO, joint-stock commercial banks have also risen in various places, and the number of branches established by foreign banks in China has gradually increased, showing that they were once monopolized as China's financial industry continues to reform and develop. The status of the four state-owned joint-stock commercial banks has been shaken.

This paper focuses on the definition and characteristics of the new generation of employees, using Bank X as an example, the current development of Bank X and the current development of the new generation of Bank $X$ employees, and the negative impact of the new generation of Bank X employees after their departure. A comprehensive analysis of the reasons for their resignation was conducted, and on this basis, the countermeasures were put forward to reduce the turnover rate of the new generation of employees in state-owned commercial banks, hoping to provide a proper resignation management plan, so that Bank X can proceed from its own reality and strengthen the state-owned company. The commercial bank management and construction adopt corresponding strategies to reduce the turnover rate of the new generation of employees and stabilize the countermeasures of talent team building.

Keywords: state-owned commercial banks; the new generation of employees; leave management

\section{Introduction}

The new generation group is an alienated group that has never previously existed. This group was born under the historical background of rapid changes of the country. The "only child policy", "restoration of the college entrance examination (CEE) system after the Cultural Revolution", "college enrollment expansion system", "rapid development of market economy", as well as the continuous shocks and fusion of various cultures or subcultures

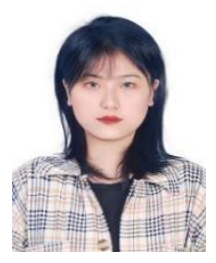

\footnotetext{
Huangrongshang Chen

Lecturer, Rangsit university, Pathum Thani, Bangkok, Thailand

Research interest: management, HRM, models of innovative HRM

E-mail: h.chen@ rangsit.ac.th
} 
have all pushed this group towards group characteristics different from any other time in history (Bannister et al., 1986). It is also for this reason that this group becomes more thoughtful, more aspirant to value and self-realization.

Bank $\mathrm{X}$ is one of the four major state-owned commercial banks in China. Although there is no shortage of new hires, the career choice ideas of new generation employees are affected, for other private banks and foreign banks have been growing in China in recent years, and the upward pressure of non-performing loans also continues to rise in recent years, including the emergence of some new forces in Internet finance, for example, the rise of ecommerce.

For instance, for a given state-owned commercial bank, a total of 351 new generation employees had left their jobs from 2013 to 2017 (William, 1977; Linghu, 2013). On the other hand, its retention rate of new generation employees was also lower than that of the peers. According to an internal survey within the organization, more than $50 \%$ of the new generation employees felt repulsive or disgusted with the internal management system or business mechanism of the organization, and a considerable number of people thought of leaving the company (Hom et al., 1984).

From here, we can see that problems such as job-hopping trend, the inadequacy of management mechanism and chaotic career planning will lead to turnover intention among new generation employees, which exerts an impact to be reckoned with on the stability and development of the organization. Therefore, for studies on the turnover intention among new generation employees, how to stabilize the organization, how to stabilize "impetuous" new generation employees, and how to reduce the turnover intention among new generation employees have become problems confronting the major business organizations today.

By far, the academic circles haven't reached a systematic and explicit understanding and yardstick on the importance and necessity of the turnover of new generation employees in state-owned commercial banks, which also makes state-owned commercial banks unable to fully exert their due value and effect under the social reality of turnover of new generation employees.

In light of the above reasons, in this project, by taking Bank $\mathrm{X}$ as an example, we analyze the reasons and problems existing in the turnover of new generation employees in current state-owned commercial banks, finds out the specific reasons for the current turnover of new generation employees in Bank $\mathrm{X}$ and presents constructive suggestions in view of these problems and reasons.

\section{Materials and Methods}

\section{Definition of New Generation Employees}

In the society today, there is an emerging working group- new generation employees. No consensus has been reached on the understanding of this group at home and abroad. The academic circles classify laborers according to the time of birth or time of starting to work, and call this group "Generation Y", "Millennials" or "Net Generation".

In foreign studies, relevant research is categorized by age. In a related work, Hansford (2002) defined Generation Y as people born between 1980 and 2000. Classified labor into three types: "Boomers(born 1946-1964)", " Gen X'ers (born 1065-1981)" and "Generation Y", into four structures, "Generation Y" refers to people born between 1982 and 1999, with a span of 17 years. In studies at home, called those born after the 1980s, growing up together 
with the knowledge economy and information age, which were aged between 20 and 35 and had just entered the workplace, the new generation.

Scholars represented came up with two criteria for new generation employees, one being born after 1980, and the other being the principal force in the workplace.

In our study, the new generation employees are defined by the time of birth, which generally refer to young employees below the age of 35 , that is, workers born after the $1985 \mathrm{~s}$ and 1990s.

This paper mainly takes the employee turnover models created by the following three scholars as the footholds:

(1) March-Simon (1958) model

Mark-Simon model is called the "participants' decision" model, which mainly revolves around the rationality and ease for employees to leave the enterprise. This model is composed of two models. From the perspectives of employee and enterprise, one is on the rationality for employees to leave the enterprise(as shown in Fig. 1) and the other on about the ease for employees to leave the enterprise(as shown in Fig. 2).

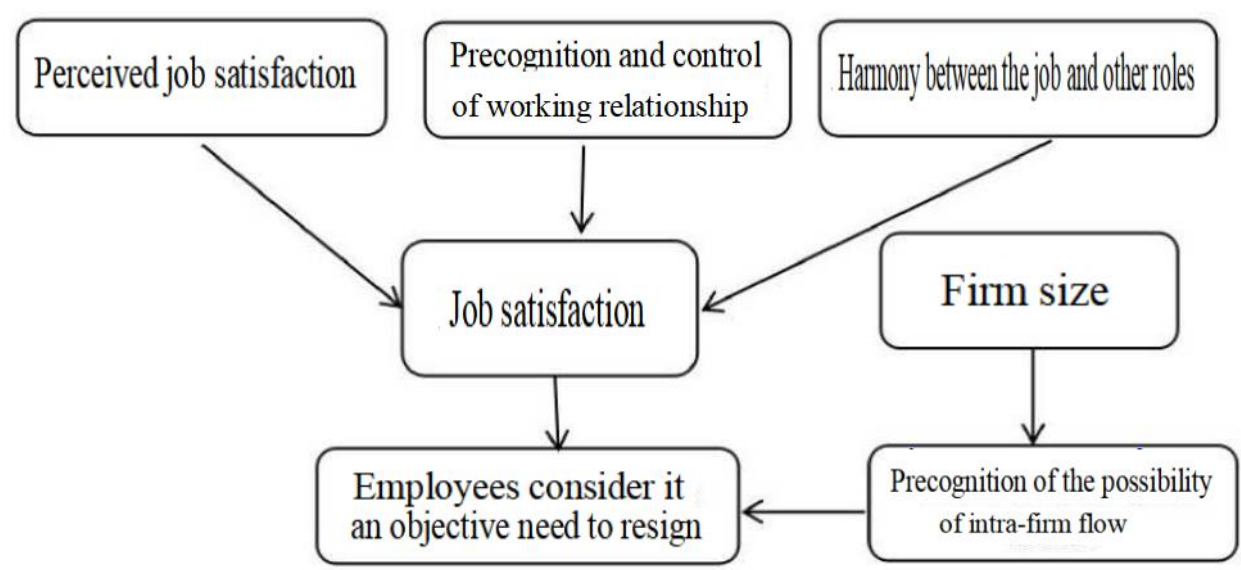

Figure 1 - Model on the Rationality of Employee Turnover (source: Mark-Simon, 1958)

Employees' satisfaction with their jobs and the possibility of inter-firm mobility are important determinants in them. There is some correlation among job satisfaction, job competence and control of working relationship. The level of remuneration, the leadership style of managers, job involvement, educational background and promotion determine whether or not an employee can achieve his or her self-worth.

From the angle of employees, the decisive factors of the ease of turnover include the number of external enterprises to choose from, the employees' personality, the availability of positions that employees are competent for and the willingness to take the positions, etc. Laying stress on the psychology and behavior of employee turnover, this paper will examine factors underlying the turnover of new generation employees, by taking job satisfaction and job opportunity as important considerations. 


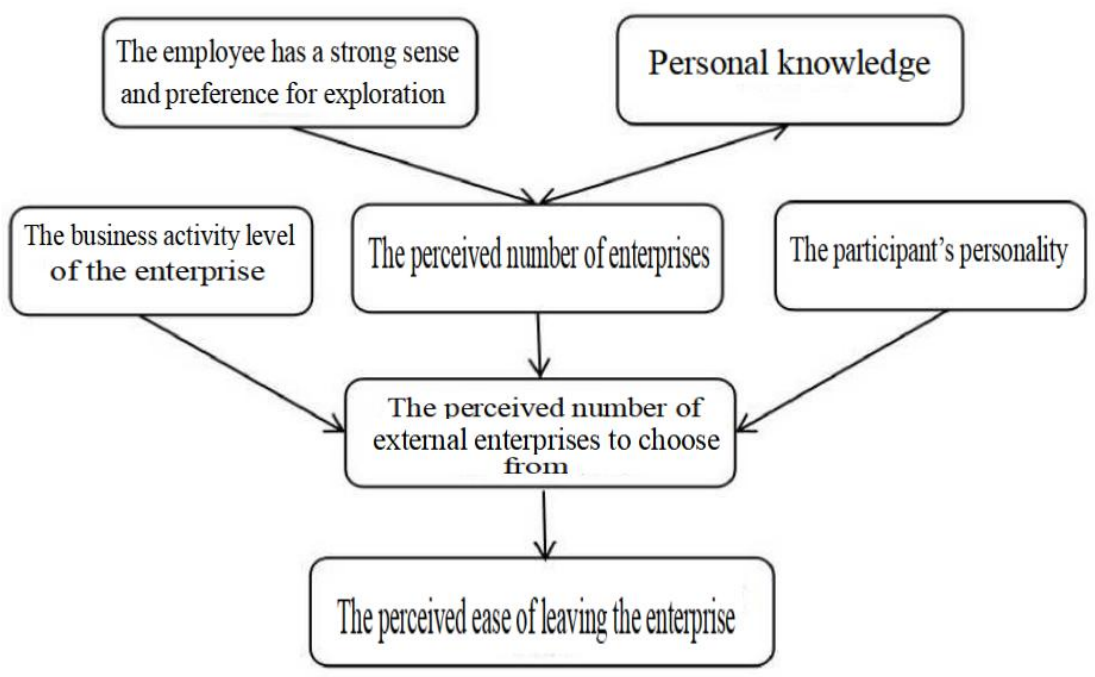

Figure 2 - Model on the Ease of Employee Turnover (source: Mark-Simon, 1958)

(2) Mobley (1977) model

Mobley (1977) was an improvement made on the basis of March-Simon model. In view of the different labor markets corresponding to different types of labor, a theoretical model for employee turnover selection is set up.

What is introduced here is the extended Mobley model. The constructer of the extended Mobley model combines multiple variables of personnel by using graphical method, in the hope of capturing all kinds of influence factors of employee turnover as comprehensively as possible.

This model is determined by four factors during the process from the occurrence of turnover intention to real departure from the enterprise, the first is the expected return of other internal positions, the second is job satisfaction, the third is the expected return of external enterprises, and the fourth is non-work values and non-work roles of the employee. This model is an intermediate linkage model, as shown in Fig. 3.

This model explicitly points out that the employee's turnover intention alone is the variable that leads to employee turnover. In this paper, while studying how new generation employees make a choice between leaving or remaining in Bank X, we take employees' individual choice as an inducement, extends it to a process of ongoing comparison between extended psychological intention and demission behavior and analyzes a series of related links from inducement to turnover. 


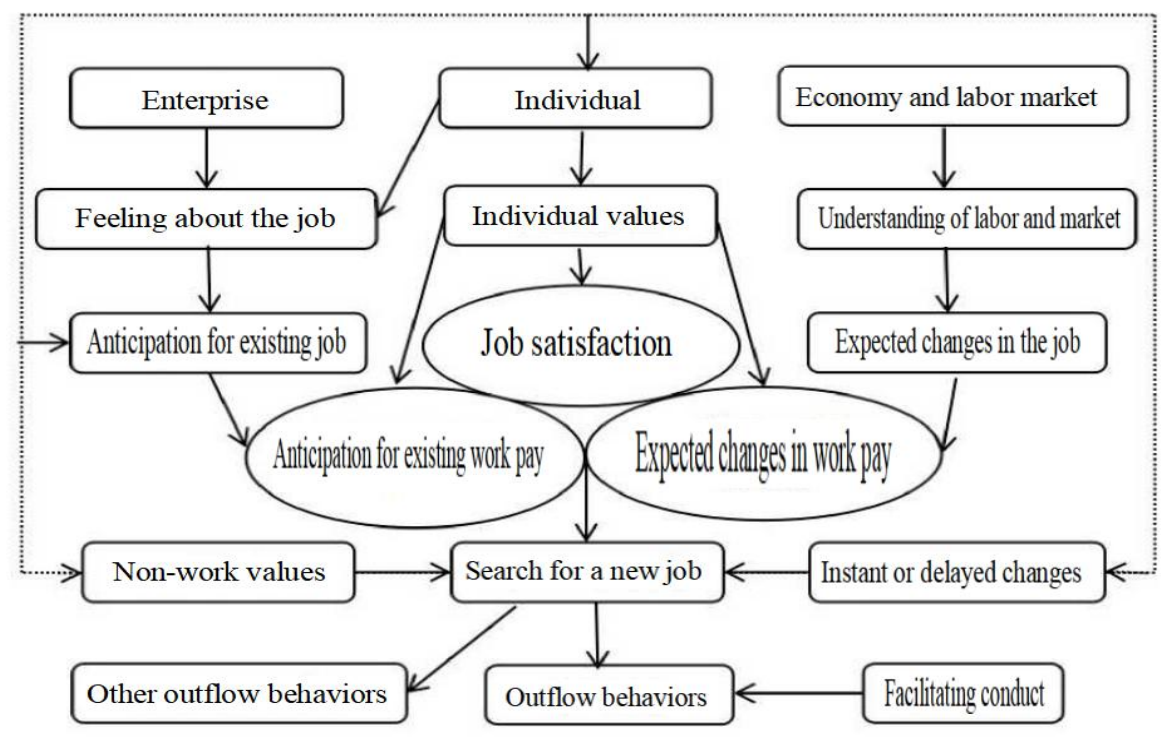

Figure 3 - Extended Mobley Model (1978)

(source: Mobley, 1977)

(3) Price-Mueller model

Price is an accomplished expert on the issue of employee turnover in the United States. The Price-Mueller (Jing, 2016) model is a model revised from the Price-Mueller model, on the basis of the research findings in key fields of multiple disciplines (as shown in Fig. 4).

Its core theory is found upon a series of hypotheses, such as the employees enter an enterprise with certain expectations, the relationship between employees and enterprise is interchange (Hansford, 2002).

The Price-Mueller model includes four types of variables involving turnover, the first is environmental variables (kinship responsibility and opportunity), the second is individual variables (training mechanism, job involvement and subjective emption at work), the third is structured variables (job monotony, social support, job stress, distribution fairness, work autonomy, promotion opportunities) and the fourth is process variables (job-seeking behavior, job satisfaction, organizational commitment and turnover intention).

When analyzing the psychological process of employee turnover, the Price-Mueller model shows strong predictive power. The analysis scope includes the relationship between multiple variables and turnover intention, which is of important significance and applicability for the setup of an early warning model for the turnover of new generation employees. 


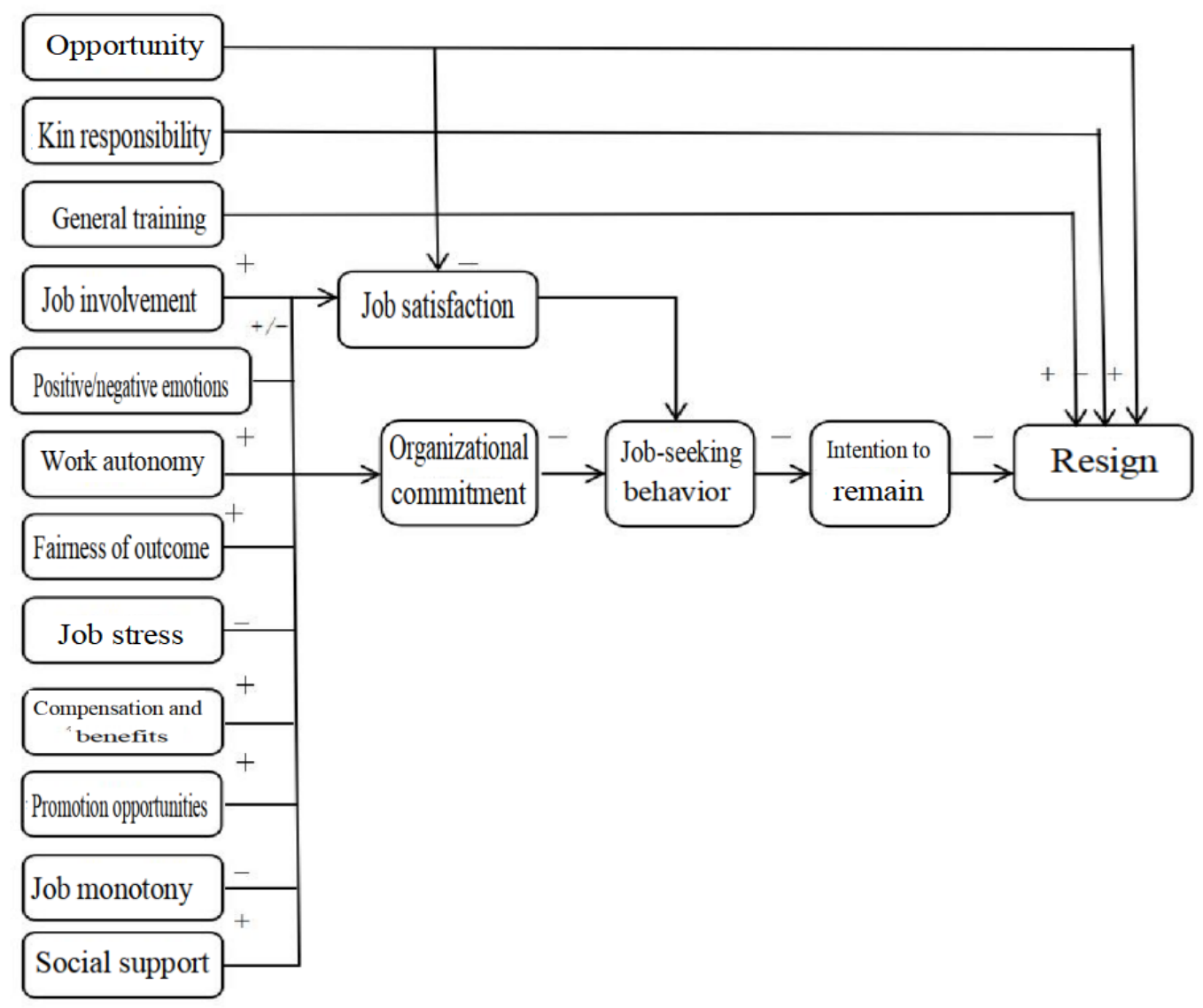

Figure 4 - Price-Mueller Model

(source: Jing, 2016)

In this study, questionnaire and interview design are taken as the main methods to obtain data:

(1) Questionnaire design: there are many factors underlying the turnover of new generation employees. In an effort to investigate the turnover of new generation employees in Bank X more accurately, and analyze the signs of the turnover of new generation employees, the author designs a questionnaire based on the Price-Mueller model and a turnover intention scale and carried out a questionnaire survey with all employees on active duty throughout Bank $\mathrm{X}$ as the respondents, by using "a questionnaire on the turnover intention of employees". This questionnaire consists of five parts: firstly, personal profile; secondly, the employees' feeling about their own work; thirdly, the employees' views on corporate culture; fourthly, the employees' opinions on compensation and benefits, training system and development space, and fifthly, turnover intention.

(2) Interview design: to understand all of the factors that affect the turnover of employees in Bank $\mathrm{X}$ in a more comprehensive and accurate way, the author designs an interview outline according to the years of working, position and nature of work of the employees, carries out one-on-one interviews through telephone, interview and social platform, etc. and records the interview results.

The influence factors of turnover are sorted out according to the interview results. The interview is approached from three aspects: individual factors, internal factors and external factors. The ultimate goal of the interview is to provide reference for the establishment of a 
questionnaire on the turnover intention of new generation employees in Bank $\mathrm{X}$ and the influence factors of turnover intention.

\section{Results and Discussion}

According to the questionnaire survey, the main motivation for the employees of Bank $\mathrm{X}$ to leave their jobs is shown in Fig. 5.

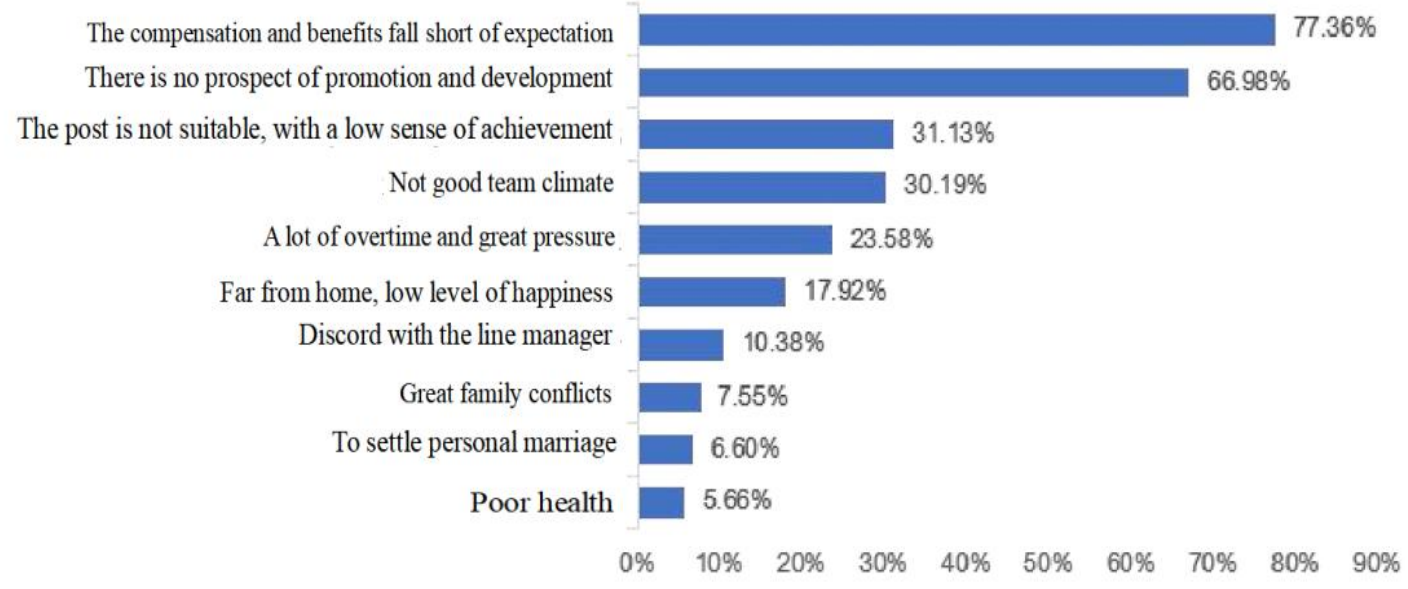

Figure 5 - Main Motivations for Employees to Resign

(made by the author)

Based on the turnover factor results in the foregoing literature review (Ni et al., 2009; Tushman et al., 2012), it is concluded that the factors underlying the turnover of new generation employees in this study mainly include individual reasons, job satisfaction, compensation and benefits, job stress, individual vision, team climate and recruitment of external positions, etc. The statistics of turnover factors are shown in Tab. 1.

From the above results of interview and questionnaire it can be concluded that the turnover of employees in Bank $\mathrm{X}$ is affected by the following three factors:

(1) Individual factors affecting the turnover of new generation employees:

First of all, the compensation and benefits fall short of expectation.

Secondly, there are impacts from the environmental, such as the family, commuting and accommodation.

Thirdly, the recognition of corporate culture is low.

(2) Internal factors affecting the turnover of new generation employees:

Firstly, the compensation and benefit system is unreasonable.

Secondly, the recruitment system is imperfect.

Thirdly, the management system is not sound.

(3) External factors affecting the turnover of new generation employees

Firstly, the development of the labor market.

Secondly, job opportunities in the financial sector have grown. 
Thirdly, the kinship responsibility is taken seriously.

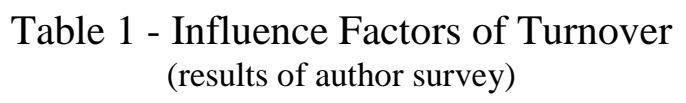

\begin{tabular}{|l|c|c|c|}
\hline \multicolumn{1}{|c|}{ Turnover Factor } & $\begin{array}{c}\text { The Number of } \\
\text { Affected People } \\
\text { Leaving the } \\
\text { Company }\end{array}$ & $\begin{array}{c}\text { Total Number of } \\
\text { Respondents }\end{array}$ & $\begin{array}{c}\text { Estimated } \\
\text { Percentage }\end{array}$ \\
\hline To settle marriage & 4 & 45 & $1.76 \%$ \\
\hline Great family conflicts & 9 & 45 & $3.96 \%$ \\
\hline Poor health & 4 & 45 & L76\% \\
\hline $\begin{array}{l}\text { The compensation and benefits fall } \\
\text { hhort of expectation }\end{array}$ & 35 & 45 & $15.42 \%$ \\
\hline $\begin{array}{l}\text { It is hard to convert to a permanent } \\
\text { worker because of the high appraisal } \\
\text { indicators }\end{array}$ & 24 & 45 & $10.57 \%$ \\
\hline $\begin{array}{l}\text { There is no prospect of promotion } \\
\text { and development }\end{array}$ & 29 & 45 & $12.78 \%$ \\
\hline The work is boring and monotonous & 16 & 45 & $7.05 \%$ \\
\hline The company is far from home & 19 & 45 & $37 \%$ \\
\hline Heavy task and great pressure & 22 & 45 & $9.69 \%$ \\
\hline Not goodteam climate & 11 & 45 & $4.85 \%$ \\
\hline $\begin{array}{l}\text { The post is not suitable, with a low } \\
\text { sense of achievement }\end{array}$ & 15 & 45 & $6.61 \%$ \\
\hline $\begin{array}{l}\text { An interbank has settled down in } \\
\text { Bank X }\end{array}$ & 22 & 45 & $9.69 \%$ \\
\hline $\begin{array}{l}\text { Admitted to an administrative } \\
\text { institution through examination }\end{array}$ & 15 & 45 & $6.61 \%$ \\
\hline To pursue further studies & 2 & 45 & $0.88 \%$ \\
\hline
\end{tabular}

To sum up, Bank X needs to carry out management over the turnover intention of new generation employees.

A regression analysis is conducted on the employees' turnover intention. A regression model is built, with job stress, individual development, kinship responsibility, job satisfaction, communication with leaders, recognition of corporate culture, rationality of salary assessment, fairness of salary assessment, satisfaction with the recruitment system, business prospect and trade union activities as the independent variables, with turnover intention as the dependent variable, as shown in Tab. 2.

\section{Dependent variable: turnover intention}

There can be multicollinearity of variables in the test model. In other words, due to the high correlation or precise correlation between the explanatory variables, the accuracy of the model is affected, and distortion or deviation occurs.

Based on an SPSS analysis, we can learn that the value of the maximum variance inflation factor (VIF) is 4.138, which is consistent with the standard of 0-10. There is no such problem as collinearity. 
Table 2 - Regression Model of Dependent Variables of Turnover (results of author survey)

\begin{tabular}{|c|c|c|c|c|c|}
\hline \multirow[b]{2}{*}{ Model } & \multicolumn{2}{|c|}{ Unnormalized Coefficient } & \multirow[b]{2}{*}{$\begin{array}{c}\text { Normalized } \\
\text { Coefficient Beta }\end{array}$} & \multicolumn{2}{|c|}{ Collinearity Statistics } \\
\hline & B & $\begin{array}{l}\text { Standard } \\
\text { Error }\end{array}$ & & Tolerance & VIF \\
\hline (Constant) & 0.272 & 0.236 & & & \\
\hline Job satisfaction & 0.258 & 0.115 & 0.237 & 0.307 & 3.255 \\
\hline Job stress & -0.14 & 0.083 & -0.147 & 0.447 & 2.236 \\
\hline Kinship responsibility & -0.086 & 0.055 & -0.115 & 0.646 & 1.547 \\
\hline Individual development & 0.304 & 0.069 & 0.376 & 0.464 & 2.156 \\
\hline \begin{tabular}{|l|} 
Recognition of \\
corporate culture
\end{tabular} & 0.189 & 0.091 & 0.157 & 0.594 & 1.684 \\
\hline $\begin{array}{l}\text { Communication with } \\
\text { leaders }\end{array}$ & 0.033 & 0.102 & 0.025 & 0.571 & 1.753 \\
\hline $\begin{array}{l}\text { Rationality of salary } \\
\text { assessment }\end{array}$ & 0.104 & 0.074 & 0.111 & 0.544 & 1.839 \\
\hline $\begin{array}{l}\text { Fairness of salary } \\
\text { assessment }\end{array}$ & -0.01 & 0.091 & -0.011 & 0.368 & 2.721 \\
\hline $\begin{array}{l}\text { Satisfaction with the } \\
\text { recruitment system }\end{array}$ & 0.139 & 0.117 & 0.142 & 0.242 & 4.138 \\
\hline Business prospect & 0.228 & 0.093 & 0.221 & 0.417 & 2.399 \\
\hline Trade union activities & -0.025 & 0.09 & -0.024 & 0.452 & 2.212 \\
\hline
\end{tabular}

$\mathrm{R} 2=0.185$, adjusted it as $\mathrm{R} 2=0.176, \mathrm{~F}=20.201, \mathrm{p}<0.01$

As can be seen from the coefficient table, the regression coefficients of job satisfaction, individual development, recognition of corporate culture and business prospect pass the significance test and are distinctly different from zero ( $\operatorname{Sig}<0.05)$, which indicates that job satisfaction, individual development, recognition of corporate culture and business prospect can significantly positively predict turnover intention.

Accordingly, the regression equation between employees' turnover intention and the influence factors can be summarized as: the employees' turnover intention $=0.376 *$ individual development $+0.237 *$ job satisfaction $+0.157 *$ recognition of corporate culture $+0.221 *$ business prospect. In the end, an indicator system for the turnover intention of new generation employees in Bank $\mathrm{X}$ is set up. The indicators involved and weight distribution is shown in Tab. 3:

Table 3 - Indicators of the Turnover Intention of New Generation Employees in Bank X (results of author survey)

\begin{tabular}{|l|c|}
\hline Indicators & Weight \\
\hline Individual development & 0.376 \\
\hline Job satisfaction & 0.237 \\
\hline Recognition of corporate culture & 0.157 \\
\hline Business prospect & 0.221 \\
\hline
\end{tabular}




\section{Establishment of Prevention Grades for Bank X}

In the process of the determination of prevention grades, five prevention grades (from low to high) are identified based on previous years' data of employee turnover in Bank X, combined with consultation with relevant specialists.

The detailed grading is dwelled on in Tab. 4:

Table 4 - Prevention Grades

(results of author survey)

\begin{tabular}{|l|c|}
\hline Grade & Corresponding Score \\
\hline Normal & $\mathrm{yW} 1$ \\
\hline Low-risk & $1 \mathrm{yW} 2$ \\
\hline Higher-risk & $2 \mathrm{VyW} 3$ \\
\hline High-risk & $3 \mathrm{VyW} 4$ \\
\hline Very high-risk & $4 \mathrm{VyW} 5$ \\
\hline
\end{tabular}

Through the classification of five grades, y represents the employees' turnover intention. When the turnover intention score is greater than 1 , it is necessary to take precautions against relevant employees. Different scores stand for different grades and the degrees of prevention. When new generation employees show intentions to leave, the prevention team should be poised for action, fully monitor the implementation process, track and feedback the results of action. The activity of proposing corrective suggestions is the socalled feedback and correction.

\section{Conclusion}

According to the above analysis, we actively seek feasible, scientific and effective solutions for Bank X, and come up with corresponding countermeasures. The root cause to consider when solving the problem is the characteristics of new generation employees. It is on this basis that the turnover problem is analyzed and solved.

First of all, since new generation employees is the principal force of corporate development, their departure will exert a negative impact on the human resources management of Bank $\mathrm{X}$ in every way. For this reason, to ensure the effective implementation of turnover intention policy, it is necessary to establish specialized turnover intention team.

Secondly, from individual new generation employees, they are more "economyconscious" than old generation employees, attach importance to interests, pursue democracy and value career development, so Bank X should make appropriate changes in its promotion system, make the management system more democratic, and emphasizes satisfying employees' sense of accomplishment. Thirdly, the learning ability and innovation awareness of new generation employees are stronger than those of old generation employees.

Perfecting employee training and encouraging their individual learning can better satisfy the features of new generation employees who attach importance to individual development, and also better enhance the working ability and promote the working enthusiasm of new generation employees. 
Finally, from the perspective that new generation employees pursue the balance between life and work, but have poor mental resistance to outside forces, it is imperative to adjust the individual welfare system for employees flexibly as appropriate and pay attention to improving the group cohesion. The working philosophy of alternating work with rest is more in line with the characteristics of new generation employees.

\section{Scientific and effective solutions}

Only by bringing up corresponding countermeasures in view of the characteristics of new generation employees can the devotion and pay-off for new generation employees be improved, and the dissatisfaction and disappointment of new generation employees with Bank X be solved. Only in this way can the value conflict inside new generation employees be solved, the employees' sense of affiliation to Bank $X$ is enhanced and the turnover management of new generation employees in Bank $\mathrm{X}$ be handled properly.

\section{Acknowledgement}

It is a great honor to receive guidance from Dr. Yang Shucheng. With a rigorous and patient attitude, he has offered me a lot of help and guidance during the whole research and writing of this paper, with his expertise. Here, I would like to express my heartfelt thanks to Dr. Yang Shucheng, my supervisor. At the same time, I am also deeply indebted to the help of my classmates and the support of my family in the completion of this paper.

\section{References}

Bannister, D. B. (1986). Applying a causal analytic framework to the Mobley, Horner and Hollingsworth turnover model: a useful reexamination. Journal of Management, 12(3): 433-443.

Hansford, D. (2002). Insight into managing an age-diverse workforce.Workspan, 45(6): 48-54.

Hom, P. W., Griffeth, R. W. \& Sellaro, C. L. (1984). The validity of Mobley's model of employee turnover. Organizational Behavior \& Human Performance, 34(2): 141-174.

Jing, M. (2016). A research on the loss of teachers in private colleges based on Price-Mueller model. Journal of Henan Institute of Science and Technology. 13.

Linghu, K. R. (2013). The job-leaving of new generation farmer workers: analysis of causes and measures based on the Price-Mueller model. Journal of Guizhou Minzu University (Philosophy and Social Science). 4 (129).

Ni, F. Y., Su, C. C., Chung, S. H. \& Cheng, K. C. (2009). The impact of budget participation on manager effectiveness: the intermediary role of self-efficacy and attitude. Management essays of National Taiwan University, 19.

Tushman, M., Lakhani, K. \& Lifshitz-Assaf, H. (2012). Open innovation and organization design. Journal of Organization Design, 1(1).

Paper submitted

Paper accepted for publishing

Paper published online
11 July 2021

28 August 2021

30 September 2021 